\title{
Executive function and theory of mind as predictors of aggressive and prosocial behavior and peer acceptance in early childhood
}

\author{
Sarah E. O'Toole | Claire P. Monks | Stella Tsermentseli
}

Department of Psychology, Social Work and Counselling, University of Greenwich, London

\section{Correspondence}

Sarah E. O'Toole, Department of Psychology, Social Work and Counselling, University of Greenwich, London.

Email: s.e.poland@greenwich.ac.uk

\begin{abstract}
Executive function (EF) and theory of mind (ToM) are related to children's social interactions, such as aggression and prosocial behavior, as well as their peer acceptance. However, limited research has examined different forms of aggression and the moderating role of gender. This study investigated links between EF, ToM, physical and relational aggression, prosocial behavior and peer acceptance and explored whether these relations are gender specific. Children $(N=106)$ between 46- and 80-months-old completed tasks assessing cool and hot EF and ToM. Teaching staff rated children's aggression, prosocial behavior, and peer acceptance. EF and ToM predicted physical, but not relational, aggression. Poor inhibition and delay of gratification were uniquely associated with greater physical aggression. EF and ToM did not predict prosocial behavior or peer acceptance. Added to this, gender did not moderate the relation between either EF or ToM and social outcomes. The correlates of aggression may therefore differ across forms of aggression but not between genders in early childhood.
\end{abstract}

\section{KEYWORDS}

aggression, executive function, peer acceptance, prosocial behavior, theory of mind

\section{1 | INTRODUCTION}

According to models of social behavior developed from the neuroscience literature, children's emerging social behaviors are dependent on their cognitive abilities, including executive function (EF) and theory of mind (ToM; Beauchamp \& Anderson, 2010; Yeates et al., 2007). EF refers to higher-order, cognitive skills required for goal-directed behavior (Goldstein, Naglieri, Princoptta, \& Otero, 2014). ToM is the ability to attribute mental states (e.g., beliefs, desires, intentions) to oneself and others in order to predict and explain behavior and is highly related to EF (Wimmer \& Perner, 1983). Children demonstrate substantial gains in their EF and ToM during early childhood (Anderson, 2008; Wellman, Cross, \& Watson, 2001). Further, in early childhood children begin school and are introduced to the peer group, 
providing them with an opportunity to learn, practice, and adapt their social skills (Warnes, Sheridan, Geske, \& Warnes, 2005). Children with greater EF and ToM abilities are better able to adapt to novel social situations, inhibit maladaptive behaviors and understand the perspectives of others (Anderson, 2008; Astington, 2003). Consequently, children with superior EF and ToM may demonstrate greater prosocial behavior and peer acceptance and less aggressive behavior (Gini, 2006; Gomes \& Livesey, 2008; Masten et al., 2012). These early peer experiences may have implications for children's later academic, social, and psychological adjustment (Yeates et al., 2007).

Although much research attention has been directed toward understanding the role of EF and ToM in children's social interactions (Gini, 2006; Jacobson Williford, \& Pianta, 2011; Masten et al., 2012), important questions concerning these relations remain. Despite social neuroscience models (Beauchamp \& Anderson, 2010; Yeates et al., 2007) highlighting the importance of both cognitive and affective EF skills in social behavior, studies have typically focused on the role of emotionally-neutral cognitive skills. EF has been differentiated into cool cognitive processes, (e.g., inhibition, working memory, planning), which are involved in abstract, emotionally neutral problems and hot affective processes (e.g., ability to delay gratification, affective decision making), which are tapped by emotion laden problems (Zelazo \& Müller, 2002). There is a strong body of evidence that poor cool EF, particularly inhibition, is related to increased aggression, decreased prosocial behavior and lower peer acceptance (Jacobson et al., 2011; Masten et al., 2012; Utendale, Hubert, Saint-Pierre, \& Hastings, 2011).

Social interactions are emotionally significant situations and are therefore likely to involve hot EF to the same or greater extent than cool EF (Zelazo \& Müller, 2002). Emerging research suggests that better hot EF is related to greater prosocial behavior in children ages 2-5 years (Di Norcia, Pecora, Bombi, Baumgartner, \& Laghi, 2015; Garner \& Waajid, 2012). Children (4- to 6-years-old) with superior EF, including hot delay of gratification, experienced greater peer acceptance (Masten et al., 2012). These studies, though, failed to examine the role of individual cool and hot EF skills in prosocial behavior and peer acceptance. Findings regarding the role of hot EF in aggressive behavior have been mixed. Some studies have reported that poor hot EF is associated with aggressive behavior in children ages 2-5 years (Di Norcia et al., 2015; Garner \& Waajid, 2012; Kim, Nordling, Yoon, Boldt, \& Kochanska, 2014), whereas other research has failed to find a relation, beyond that of cool EF in children ages 3-6 years (Poland, Monks, \& Tsermentseli, 2016; Willoughby, Kupersmidt, Voegler-Lee, \& Bryant, 2011). Understanding the links between cool and hot dimensions of EF and social behaviors, like aggression, may enable more targeted interventions to be developed.

A further question that remains is whether EF and ToM predict all types of aggression. Aggression is no longer considered one heterogeneous category of behaviors, but has been posited to consist of distinct forms of aggression. The main forms of aggression that have been studied are physical (e.g., hitting) and relational (e.g., social exclusion; Crick, Casas, \& Ku, 1999). Physical and relational aggression follow distinct developmental trajectories (Tremblay, 2000; Vaillancourt, Miller, Fagbemi, Côtè, \& Tremblay, 2007), are differently predicted by parenting styles (Russell, Hart, Robinson, \& Olsen, 2003) and are associated with varying outcomes (Card, Stucky, Sawalani, \& Little, 2008). These forms of aggression may consequently be related differently to EF and ToM.

Studies of children 9- to 17-years-old found that poor EF was associated with higher levels of physical aggression, but was unrelated to relational aggression (Dane \& Marini, 2014; Terranova, Morris, \& Boxer, 2008). However, another study with 9- to 12-year-olds reported that poor EF was related to both physical and relational aggression (McQuade, Murray-Close, Shoulberg, \& Hoza, 2013), although only one cool EF skill, working memory, was considered. The role of $\mathrm{EF}$ and ToM in forms of aggression in younger children is not well understood. Research with 3- to 6-year-olds has found that both physical and relational aggression are related to EF (Poland et al., 2016). However, ToM was found to be negatively related to physical aggression and unrelated to relational aggression in 3- to 5-year-olds (Renouf et al., 2010; Werner, Cassidy, \& Juliano, 2006). The underlying role of cognitive abilities in forms of aggression may vary depending on the cognitive processes being assessed. Relational aggression, for example, may require intact ToM due to the need to understand social relationships.

The present research aimed to elucidate the relations of EF and ToM to aggression, prosocial behavior and peer acceptance in early childhood, a sensitive period in children's cognitive and social development. Identifying the roles of EF and ToM in these social outcomes will provide a more comprehensive understanding of social behavioral 
development. Further, this study may inform more targeted interventions that may reflect the specific needs of physically or relationally aggressive children. This study addressed two important limitations in the literature. First, the role of hot, as well as cool, EF in social behaviors was examined. Identifying the role of hot EF in social development may increase understanding of correlates of social behavior outside the laboratory, where social interactions are unlikely to be devoid of emotion. Second, the current study assessed both physical and relational forms of aggression. Identifying the underlying cognitive processes of subtypes of aggression may increase knowledge of how children are using aggression in real life.

The moderating role of gender was also examined. Several researchers have argued that a gender-based approach to the study of social behaviors is needed to identify patterns of development specific to each gender (Ostrov \& Godleski, 2010). A meta-analysis found that physical aggression is more common in boys whereas relational aggression is more typical of girls (Card et al., 2008). Though, gender differences in relational aggression may be characteristic of adolescence (Archer, 2004). Girls (8-15 years) are also rated as more prosocial and accepted by their peers (Smith, Rose, \& Schwartz-Mette, 2009; Zimmer-Gembeck, 2005). This may be reflective of differences in the organization of girls' and boys' peer groups. Girls tend to form smaller more exclusive peer groups than boys (Lagerspetz, Björkqvist, \& Peltonen, 1988). Girls have also been found to exhibit greater EF and ToM skills (Gur et al., 2012). Added to this, poor ToM has been found to be related to physical aggression in boys, but not girls, ages 3-5 years (Walker, 2005; Werner et al., 2006). Relational aggression was not related to ToM for boys or girls. The role of ToM in prosocial behavior across genders is unclear, with some research finding a relation only in girls (3-5 years; Walker, 2005) and others in boys (4-5 years; Yagmurlu, 2013). The role of cognitive abilities in aggression may therefore vary across genders, especially in early childhood.

Based on the findings of prior studies (Gini, 2006; Gomes \& Livesey, 2008; Masten et al., 2012), it was hypothesized that cool and hot EF and ToM would be associated with prosocial behavior and peer acceptance. However, it was predicted that EF and ToM would be related to physical but not relational aggression as prior findings have indicated that poor behavioral control and social understanding are related to physical, but not relational aggression (Dane \& Marini, 2014; Werner et al., 2006). Prior studies investigating gender-specific relations are limited and have resulted in mixed findings, especially for prosocial behavior (Walker, 2005; Yagmurlu, 2013). Specific hypotheses regarding the moderating role of gender were therefore not made.

\section{METHOD}

\section{1 | Participants}

The sample included 106 children (51 males and 55 females), between 46- and 80-months-old ( $M=61.43, S D=9.76$ ), from two mainstream primary schools in the United Kingdom. These children were participating in a longitudinal investigation into the underlying cognitive factors of aggression. The schools were comparable on the percentage of pupils receiving free school meals: $26.6 \%$ and $24.7 \%$. Children selected to participate were typically developing and were not diagnosed with a mental health disorder (e.g., ADHD, ASD, conduct disorder) or a learning disability. Parent consent and child assent were obtained. Participation rate was $46 \%$. The class teachers $(n=7)$ and teaching assistants $(n=10)$ of the children involved in the study were also recruited. Informed consent was obtained from teaching staff.

\section{$2.2 \mid$ Measures}

The measures of EF and ToM were all developmentally appropriate (Carlson, 2005).

\subsubsection{Cool EF}

Children's inhibition was assessed using a computerized Fish and Shark Go/No-Go Task (Simpson \& Riggs, 2006). Children were required to catch the fish by pressing a button (Go trials), but to withhold pressing the button to avoid 
catching the shark (No-Go trials). Each child first completed 6 practice trials ( $3 \mathrm{Go}$ and 3 No-Go trials) and then 40 test trials (30 Go and 10 No-Go trials). The proportion of correct No-Go trials was calculated.

The Tower of London was used to assess children's planning skills (ToL; Shallice, 1982). Children were required to move beads on a pegboard from the starting arrangement to a goal arrangement. There were two 2-move practice problems and 12 test problems ranging from 2- to 5-moves (Shallice, 1982). Following the approach of previous research (Hughes, Dunn, \& White, 1998; Monks, Smith, \& Swettenham, 2005), children were given a maximum of 2 min per trial and up to two attempts to solve each problem, within the specified number of moves. The task was stopped after the child completed all the problems or failed two consecutive problems. Children were awarded 2 points if they completed the problem on the first trial, 1 point if they took two attempts and 0 points if they failed to complete the problem in two trials. Potential scores ranged from 0 to 24 .

Working memory was measured using the Digit Span forward and backward subtests from the WISC-III (Wechsler Intelligence Scale for Children-3rd Edition; Wechsler, 1991). Although the Digit Span was designed for use with children ages from 6- to 16-years, it has been successfully used with children below 5-years-of-age (Alloway, Gathercole, Kirkwood, \& Elliott, 2008). In the forward subtest children had to recall a number sequence in the order spoken (up to 9 digits) and in the backward subtest children had to recall the sequence in reverse order (up to 8 digits). Children were awarded 1 point for each correct trial. Scores from the forward and backward subtest were summed and potential scores ranged from 0 to 30 .

\subsection{2 $\mid$ Hot EF}

A modified version of the Child Gambling Task (CGT) developed by Kerr and Zelazo (2004) was used to measure affective decision making (for full details of the task see Poland et al., 2016). The aim of this task is to win as many beads as possible, in order to receive a greater reward at the end of the task. There were 6 demonstration trials and 50 test trials. On each trial the child selected a card from one of two decks. When turned the cards revealed happy faces, representing the number of beads won, and sad faces, representing the number of beads lost. One deck was advantageous and resulted in a win of 1 bead and a loss of either 0 or 1 beads, whereas the other deck was disadvantageous and resulted in a win of 2 beads, but a loss of either $0,4,5$, or 6 beads. The beads the child won could be traded for stickers at the end of the task. Whether predominately advantageous or disadvantageous decisions were made across the last three trial blocks was used as a measure of affective decision making.

The Gift Delay task was used to measure children's ability to delay gratification (Kochanska, Murray, Jacques, Koenig, \& Vandegeest, 1996). The child was instructed not to peek while the researcher wrapped a gift. The researcher pretended to wrap the gift in a standardized manner (rifling through a plastic bag, cutting wrapping paper with scissors, folding the paper and tearing off the tape) for $60 \mathrm{~s}$. Children received 2 points if they did not turn around, 1 point if they peeked over their shoulder and 0 points if they turned around completely.

\subsection{3 $\mid$ ToM}

False belief understanding was assessed as a measure of ToM. To assess first-order false belief understanding an Unexpected Contents and Change of Location task were used. In the Unexpected Contents task children were asked to predict the contents of a familiar sweet tube, before it was revealed that the tube contained crayons (Perner, Leekam, \& Wimmer, 1987). The child was then asked a false belief question: "If I show this box to another child in your class what will they think is inside the box?" (answer: sweets); and two control questions: "When you first saw the box, what did you think was inside?" (answer: sweets) and "What is in the box really?" (answer: crayons). In the Change of Location task the Sally-Anne story was used (Baron-Cohen, Leslie, \& Frith, 1985). Sally puts her marble in her yellow box before going out to play. Anne then hides Sally's marble in her blue box. The child was asked a false belief question: "Where will Sally look for her marble?" (answer: Sally's box); and two control questions: "Where is the marble really?" (answer: Anne's box) and "Where was the marble in the beginning?" (answer: Sally's box).

An adaptation of the Sally-Anne task was used to assess second-order false belief understanding (A. Riviere, personal communication, 1997). In this version, Sally witnessed Anne move the marble. The child was asked a true belief question, "Where will Sally look for the marble?" and a second-order false belief question, "Where does Anne think 
that Sally will look for the marble?" (answer: Sally's box). The same control questions as in the first-order variant were asked, along with an additional question: "Did Anne know that Sally was watching?" (answer: no). A composite ToM score was created. Children scored 1 point for each task they successfully completed. To pass each task the child had to answer the false belief and control questions correctly. Potential scores ranged from 0 to 3 .

\subsection{4 | Verbal ability}

The short version of the British Picture Vocabulary Scale (Dunn, Whetton, \& Pintilie, 1982) was used to assess children's receptive vocabulary. Children were required to select the picture (from four options) that best matched the word. Standardized scores according to age were used.

\subsection{5 | Behavioral measures}

Class teachers and teaching assistants completed the 12 item Preschool Proactive and Reactive Aggression Scale (PPRA) for each child in their class participating in the study to assess the function and form of aggression (Ostrov \& Crick, 2007). The PPRA consists of four subscales, with three items for each: proactive physical aggression (e.g., this child often threatens others physically to get what $s /$ he wants), reactive physical aggression (e.g., if other children make this child mad, s/he will often physically hurt them), proactive relational aggression (e.g., to get what this child wants, $s$ /he often tells others that $s / h e$ won't be their friend anymore), and reactive relational aggression (e.g., if other children hurt this child, s/he often keeps them from being in their group of friends). The PPRA had good internal consistency (proactive physical aggression, $\alpha=.91$; reactive physical aggression, $\alpha=.92$; proactive relational aggression, $\alpha=.80$; reactive relational aggression, $\alpha=.81$ ). Although both function and form were measured by the PPRA, subscales were collapsed into physical and relational measures due to high correlation between functions of aggression in the present sample. The correlation for proactive and reactive relational aggression was .95 and for proactive and reactive physical aggression was .91 .

Teaching staff also completed the four-item prosocial behavior subscale (e.g., is good at sharing and taking turns) and the two-item peer acceptance subscale (e.g., this child is well liked by peers of the same/opposite gender) from the Preschool Social Behavior Scale (Crick, Casas, \& Mosher, 1997). The prosocial behavior subscale $(\alpha=.94)$ and the peer acceptance subscale $(\alpha=.90)$ had good internal consistency. For both questionnaires, teaching staff rated how true each statement was of the child on a 5-point Likert scale, ranging from "1" meaning "never or almost never true" to "5" meaning "always or almost always true." Teaching staff scores for each subscale were averaged as they were highly and significantly correlated (proactive relational aggression $r=.42, p<.001$; reactive relational aggression, $r=.39, p<.001$; proactive physical aggression, $r=.51$, $p<.001$; reactive physical aggression, $r=.67, p<.001$; prosocial behavior, $r=.58, p<.001$; peer acceptance $r=.60, p<.001)$.

\section{3 | Procedure}

This study received ethical approval from the University's Research Ethics Committee. The present study was based on data from the first phase of a longitudinal investigation into the underlying cognitive factors of early childhood aggression. Informed consent was obtained from teaching staff and primary caregivers of children participating in the research. This study was carried out in April to June 2014. Children completed the tasks in a fixed order across three assessment sessions: session 1: CGT (affective decision making) and BPVS (verbal ability); session 2: ToL (planning), Digit Span (working memory), Sally-Anne first-order (ToM) and Go/No-Go (inhibition); session 3: Deceptive Contents (ToM), Sally-Anne second-order (ToM) and Gift Wrap (delay of gratification). Children were assessed individually in a quiet room at their school. Each assessment session lasted between 20 and $45 \mathrm{~min}$. Teaching staff completed the questionnaires at their own convenience during the testing phase. 
TABLE 1 Summary statistics for the predictors and dependent variables

\begin{tabular}{|c|c|c|c|c|c|}
\hline & $N$ & Min & Max & $M$ & SD \\
\hline \multicolumn{6}{|l|}{ Cool EF } \\
\hline Inhibition & 106 & .11 & 1.0 & .84 & .20 \\
\hline Planning & 105 & 0 & 18 & 5.33 & 4.84 \\
\hline Working memory & 106 & 0 & 15 & 7.11 & 3.18 \\
\hline \multicolumn{6}{|l|}{ Hot EF } \\
\hline Decision making & 106 & -1.0 & 1.0 & -.05 & .45 \\
\hline Delay of Grat. & 105 & 0 & 2 & 1.45 & 0.80 \\
\hline ToM & 104 & 0 & 3 & 1.42 & 0.88 \\
\hline Verbal ability & 106 & 47 & 137 & 97.36 & 16.49 \\
\hline Physical aggression & 106 & 0.50 & 4.33 & 1.77 & 0.83 \\
\hline Relational aggression & 106 & 0.50 & 4.04 & 2.20 & 0.76 \\
\hline Prosocial behavior & 106 & 2.13 & 5.0 & 3.65 & 0.72 \\
\hline Peer acceptance & 106 & 2.0 & 5.0 & 3.92 & 0.70 \\
\hline
\end{tabular}

$E F=$ Executive function; Delay of Grat = Delay of gratification; ToM = Theory of mind.

\section{3 | RESULTS}

Data were analyzed using SPSS version 22. Descriptive statistics are reported in Table 1. Pearson's correlations were carried out to examine the bivariate relations between all variables (Table 2). Gender was dummy coded: males $=1$ and females $=2$. Two children were excluded from the analysis due to missing data on at least one measure, meaning the final sample included 104 children.

TABLE 2 Correlations between variables

\begin{tabular}{|c|c|c|c|c|c|c|c|c|c|c|c|c|c|}
\hline & 1 & 2 & 3 & 4 & 5 & 6 & 7 & 8 & 9 & 10 & 11 & 12 & 13 \\
\hline 1. Age & - & - & -.11 & .15 & $.46^{* * *}$ & $.60^{* * *}$ & .09 & $.23^{*}$ & $.25^{* * *}$ & -.10 & -.08 & .11 & .17 \\
\hline 2.Gender & & - & .03 & $.24^{*}$ & .06 & .02 & .10 & $.25^{*}$ & .10 & $-.26^{* *}$ & $.19^{*}$ & .15 & -.05 \\
\hline 3. Verbal ability & & & - & $.28^{* *}$ & $.20^{*}$ & .17 & -.09 & .08 & $.20^{*}$ & -.16 & -.09 & .18 & $.20^{*}$ \\
\hline 4. Inhibition & & & & - & .18 & $.33^{* *}$ & .08 & $.42^{* * *}$ & $.25^{*}$ & $-.45^{* * *}$ & $-.22^{*}$ & $.26^{* *}$ & .14 \\
\hline 5. Planning & & & & & - & $.45^{* * *}$ & .14 & $.19^{*}$ & $.27^{* *}$ & $-.22^{*}$ & $-.21^{*}$ & .14 & .15 \\
\hline 6. Working memory & & & & & & - & -.06 & $-.23^{*}$ & $.43^{* * *}$ & $-.19^{*}$ & -.04 & $.24^{*}$ & $.27^{* *}$ \\
\hline 7. Decision making & & & & & & & - & -.05 & .09 & .10 & .07 & -.09 & -.13 \\
\hline 8. Delay of gratification & & & & & & & & - & .13 & $-.37^{* * *}$ & -.14 & $.21^{*}$ & .04 \\
\hline 9. ToM & & & & & & & & & - & $-.23^{*}$ & -.06 & $.19^{*}$ & .11 \\
\hline 10.Physical aggression & & & & & & & & & & - & $.63^{* * *}$ & $-.55^{* * *}$ & $-.19^{*}$ \\
\hline 11.Relational aggression & & & & & & & & & & & - & $-.33^{* * *}$ & -.07 \\
\hline 12. Prosocial behavior & & & & & & & & & & & & - & $.69^{* * *}$ \\
\hline 13. Peer acceptance & & & & & & & & & & & & & - \\
\hline
\end{tabular}

Note. Gender: Males $=1$ and Females $=2$.

${ }^{*} p<.05 ;{ }^{* *} p<.01 ;{ }^{* *} p<.001$, one-tailed. 
A hierarchical regression was carried out for each of the social outcomes (physical aggression, relational aggression, prosocial behavior, and peer acceptance). In the first-step child age, gender and verbal ability were entered to control for confounding effects. Age was controlled for due to the wide age span of the sample and the fact age was correlated with some measures of cognition and behavior (Table 2). Gender and verbal ability were also controlled because these variables were associated with some cognitive and behavioral domains (Table 2). In the second-step cool and hot EF and ToM predictors were entered simultaneously as EF and ToM are highly related. Then in the third step interaction terms between gender and cognitive abilities were entered to explore the potential moderating role of gender. To avoid multicollinearity between predictors and interaction terms, predictor variables were centered around their mean (Aiken \& West, 1991). Full regression results for the four social outcomes are reported in Table 3.

\subsection{Physical aggression}

Child variables significantly accounted for $14 \%$ of the variance in physical aggression, $R^{2}=.14, F(3,103)=5.25$, $p=.002$. Gender was a significant negative predictor, meaning physical aggression was more common in boys. Verbal ability was also a significant negative predictor. The addition of EF and ToM significantly increased the amount of variance in physical aggression explained to $31 \%,{ }_{\Delta} R^{2}=.17, F(6,94)=3.94, p=.001$. Inhibition and delay of gratification were significant negative independent predictors, suggesting that children with poorer inhibition and delay of gratification demonstrated greater physical aggression. The inclusion of gender interactions increased the variance explained to $36 \%$, but this increase was not significant, ${ }_{\Delta} R^{2}=.05, F(6,88)=1.24, p=.30$. Gender did not moderate the relation between either EF or ToM and physical aggression.

\subsection{Relational aggression}

Child variables did not significantly predict relational aggression, $R^{2}=.06, F(3,103)=2.28, p=.08$. The addition of $E F$ and ToM increased the amount of variance accounted for in relational aggression to $17 \%$, but this increase was not significant, ${ }_{\Delta} R^{2}=.11, F(6,94)=2.03, p=.07$. Despite this increase not being significant, inhibition and planning were significant negative independent predictors of relational aggression. EF and ToM therefore did not increase understanding of relational aggression. Further, adding the gender interactions led to $20 \%$ of the variance in relational aggression being explained, but this increase was not significant, ${ }_{\Delta} R^{2}=.03, F(6,88)=0.50, p=.81$. Gender did not moderate the relation between either EF or ToM and relational aggression.

\subsection{Prosocial behavior}

Child variables did not significantly predict prosocial behavior, $R^{2}=.07, F(3,103)=2.41, p=.07$. Though, verbal ability was a significant positive independent predictor. The inclusion of EF and ToM increased the variance in prosocial behavior explained to $13 \%$, but this increase was not significant, ${ }_{\Delta} R^{2}=.07, F(6,94)=1.21, p=.31$. Further, the addition of gender interactions accounted for $20 \%$ of the variance in prosocial behavior, but this increase was not significant, ${ }_{\Delta} R^{2}=.07, F(6,88)=1.24, p=.29$. EF and ToM did not increase understanding of prosocial behavior and these relations were not moderated by gender.

\subsection{Peer acceptance}

Child variables significantly explained $8 \%$ of the variance in peer acceptance, $R^{2}=.08, F(3,103)=3.14, p=.03$. Age and verbal ability were significant positive independent predictors. Including EF and ToM into the model increased the variance in peer acceptance explained to $13 \%$, but this increase was not significant, ${ }_{\Delta} R^{2}=.04, F(6,94)=0.73, p=.63$. The addition of gender interactions accounted for $16 \%$ of the variance in peer acceptance, but this increase was not significant, ${ }_{\Delta} R^{2}=.03, F(6,88)=0.54, p=.78$. EF and ToM did not increase understanding of peer acceptance and these relations were not moderated by gender. 


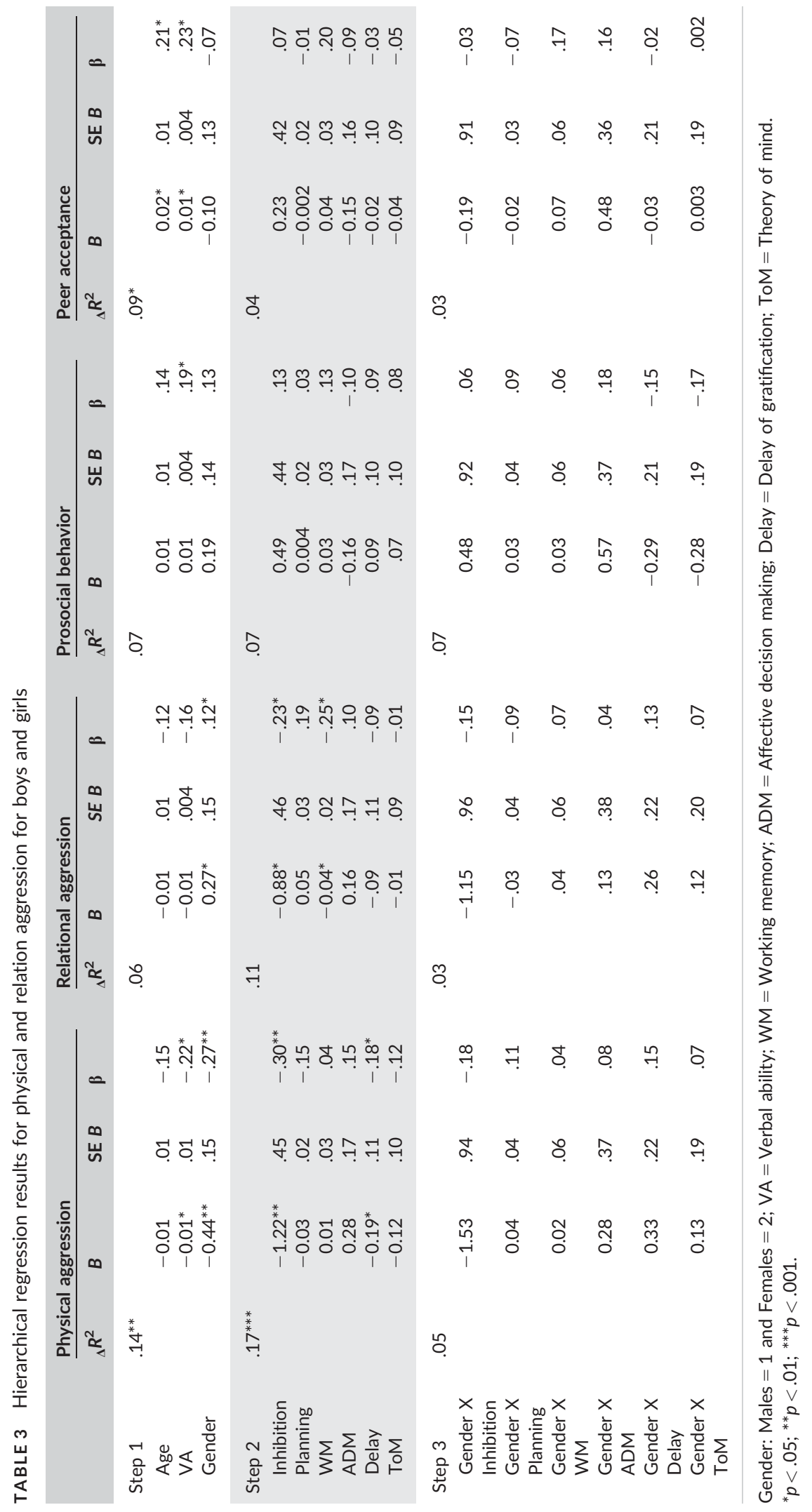




\section{4 | DISCUSSION}

The present study explored the role of cool and hot EF and ToM in early childhood (3-6-years-old) aggression, prosocial behavior and peer acceptance to gain a more comprehensive understanding of pathways of social development. In line with the hypothesis, this study indicated that cool and hot EF and ToM jointly predicted physical, but not relational, aggression. In particular, poor cool inhibition and hot delay of gratification were associated with greater physical aggression. Forms of aggression may therefore have different cognitive correlates, at least in early childhood. This relation, though, was not found to be moderated by gender. In contrast to the hypotheses, EF and ToM did not predict prosocial behavior or peer acceptance and these relations were not moderated by gender.

Building on previous studies (Dane \& Marini, 2014; Terranova et al., 2008; Werner et al., 2006), this research indicated that EF and TOM are related to physical, and not relational, aggression even in early childhood. In support of research which has suggested inhibition is central to childhood aggression (Utendale et al., 2011), poor inhibition was uniquely related to greater physical aggression. Physical aggression may be more strongly associated with inhibition than relational aggression because withholding a physically aggressive act (unlike withholding a relationally aggressive act) involves inhibiting a behavioral act and may therefore rely on greater control over one's body and actions. Functions of aggression were not included in this study, but may interact with forms of aggression in their association with cognitive abilities (Frey, Newman, \& Onyewuenyi, 2013). Poor EF may be particularly important to physical aggression when used reactively as it involves greater anger and poorer emotional regulation (Ostrov, Murray-Close, Godleski, \& Hart, 2013) and less forethought (Kempes, Matthys, de Vries, \& van Engeland, 2005) compared to proactive aggression.

Poor delay of gratification was also uniquely related to greater physical aggression, indicating that both cool and hot domains of EF were associated with physical aggression, adding to previous studies (Di Norcia et al., 2015; Garner \& Waajid, 2012; Kim et al., 2014). Physical aggression appears to be associated with impulse control in both emotionally neutral (e.g., Go/No-Go Task) and affective (e.g., Gift Wrap) situations. Aggressive interactions are emotionally and motivationally significant situations and, as a result may involve hot, as well as cool, EF (Zelazo, Qu, \& Müller, 2005). Children who are less able to delay their desire for immediate reward, may be less able to withhold an aggressive physical response and wait for a more delayed consequence (e.g., punishment from a Teacher) when a peer has provoked them or has something they want. The VM-PFC, which is thought to subserve hot EF, has been found to come online before the DL-PFC, which is associated with cool EF (Gogtay et al., 2004). Hot EF may therefore be related to physical aggression in early childhood as hot EF emerges, but may be less strongly associated with aggression in later childhood.

The relation of delay of gratification with physical aggression does not support the findings of Poland et al. (2016) and Willoughby et al. (2011), who failed to find an association between hot EF and aggression, beyond that of cool EF. However, the mean rate of aggression in Willoughby et al.'s study was low and they also failed to find an association between cool EF and aggression. Further, Poland et al. treated cool and hot EF as distinct domains of EF as their aim was to examine their unique contributions to subtypes of aggression, whereas in the present study cool and hot EF processes were considered together. EF undergoes rapid development during early childhood (Anderson, 2008) and as a result distinct cool and hot domains of EF may not be discernible in early childhood. EF may therefore be broadly related to aggression, but hot EF may not contribute to aggression beyond that of cool EF.

Relational aggression may not have been associated with EF and ToM in the current study due to the developmental stage of the sample. Physical aggression typically declines over early childhood, whereas relational aggression has been found to increase and become more indirect (aggressive acts occurring behind the victim's back) with age (Björkqvist, Österman, \& Kaukiainen, 1992). Indirect aggression is likely to be more socially sophisticated than direct aggression as it requires a greater understanding of how to manipulate social networks and the justifications needed to involve other peers (Heilbron \& Prinstein, 2008). The differential role of cognitive abilities across forms of aggression may therefore not be apparent at other stages in development, such as middle childhood. EF may become more central to relational aggression across childhood. In line with this argument, although EF and ToM did not significantly increase understanding of relational aggression, inhibition and working memory were significant independent predictors. 
In contrast to previous findings (Di Norcia et al., 2015; Garner \& Waajid, 2012; Gini, 2006), EF and ToM were not related to prosocial behavior in early childhood. The lack of an association may reflect the different ways previous research has measured prosocial behavior. For instance, some studies have obtained reports of children's prosocial behaviors, including comforting and cooperation (Jacobson et al., 2011; Masten et al., 2012), whereas other studies have gathered reports of children's social competence, which includes prosocial behaviors and positive peer interactions (Di Norcia et al., 2015; Garner \& Waajid, 2012) by parents, teachers, or peers. Further, other research has assessed children's sharing using laboratory tasks (Moore, Barresi, \& Thompson, 1998). Prosocial behavior includes a broad range of behaviors, and children may demonstrate different rates of prosocial behavior across varied contexts. Consequently, the relation between prosocial behavior and EF and ToM may vary based on who is assessing the behavior and the type of prosocial behavior measured.

Children's EF and ToM skills were also unrelated to their peer acceptance in early childhood, in contrast to previous work (Masten et al., 2012). Though, in the present study teacher reports of peer acceptance, but not peer rejection, were obtained. Peer acceptance and rejection are distinct; low peer acceptance does not necessarily mean rejection (Véronneau, Vitaro, Brendgen, Dishion, \& Tremblay, 2010). Children's cognitive abilities may be differently related to acceptance and rejection. Added to this, teachers are external to the peer group and may be less aware of children's position in the peer group. Further research should therefore focus on the role of children's cognitive abilities in peer acceptance and rejection reported by their peers. A further alternative explanation is that children's social behavior, such as aggression or prosocial behavior, may mediate the relation between cognitive abilities and peer acceptance. ToM at 5-years-old has been found to be related with peer acceptance and rejection at 7-years-old via its effect on prosocial behavior at 6-years-old (Caputi, Lecce, Pagnin, \& Banerjee, 2012). Examining indirect paths was beyond the scope of this study, but is an important avenue for future research.

Gender did not moderate the relation between either EF or ToM and aggression, prosocial behavior or peer acceptance. Gender was predictive of aggression. Physical aggression was more common in boys and relational aggression was more typical of girls, in line with previous findings (Card et al., 2008). Cool and hot EF and ToM, though, appeared to be associated with physical aggression for boys and girls in early childhood. Gender differences may become more apparent during middle childhood as girls have been found to show increasing trajectories of relational aggression, whereas boys show decreasing trajectories (Spieker et al., 2012). However, this result should be treated with caution as the sample size of the present study was relatively small and consequently the analysis may have lacked power to detect the interactions.

\section{5 | LIMITATIONS}

This study was the first to explore the associations among EF, ToM, aggressive and prosocial behavior and peer acceptance in early childhood and whether these relations were moderated by gender. However, larger scale studies are needed to replicate the present findings. Interaction effects may not have been detected due to limited power. A limitation of this study was that it was carried out at one time point, meaning indirect pathways between cognitive skills and social behaviors could not be examined. Longitudinal research would increase understanding of the direction and nature of the relation between cognitive abilities and aggression, prosocial behavior and peer acceptance across early childhood. The current research was also limited in that the socioeconomic status (SES) of the sample was not measured. SES and EF have been found to be related (Hughes, Ensor, Wilson, \& Graham, 2010) and SES may consequently be a contributing factor in children's aggression. Future research confirming these findings after controlling for SES would be beneficial. The present study is also limited in that forms, but not functions, of aggression were taken into account. Form and function may interact (Frey et al., 2013). Greater understanding of the varied development of aggression may therefore be obtained by assessing form and function. Last, the present study relied on false belief understanding as a measure of ToM. Other ToM skills, such as emotion understanding, may be implicated in children's aggressive behavior. Future research should assess a wider range of ToM skills. 


\section{6 | CONCLUSIONS}

This study highlights the importance of considering the multidimensional nature of aggression in order to increase understanding of its varied nature and outcomes. Early childhood physical aggression was predicted by EF and ToM, suggesting that the specific cognitive processes underlying aggression may vary depending on its form in early childhood. Gender differences in the relation between EF and ToM and physical aggression were not apparent, suggesting that EF and ToM are related to aggression in boys and girls. Last, EF and ToM did not predict prosocial behavior or peer acceptance. This emphasizes the need for researchers to consider a broad range of social behaviors and outcomes as the same cognitive processes may not underlie all dimensions of social interactions. The intersection of cognitive abilities and social behaviors is an important topic that warrants further investigation as understanding the types of aggression children are using and how they interact with cognition across development may help to improve intervention efforts and subsequently the outcomes for children who are demonstrating aggressive behaviors. Interventions may need to consider the type of aggression and the developmental stage of the child as one intervention method may not be effective for all types of aggressive children. For example, targeting inhibition and delay of gratification may be beneficial in reducing physical aggression (but not relational aggression) in early childhood only.

\section{ACKNOWLEDGMENTS}

This research was supported by the Vice Chancellor Scholarship from the University of Greenwich. The authors would like to acknowledge their gratitude to the participating schools and children. In addition, the authors acknowledge Jamie Ostrov for providing and advising on his questionnaire.

\section{CONFLICT OF INTEREST}

No conflicts declared.

\section{REFERENCES}

Aiken, L. S., \& West, S. G. (1991). Multiple regression. Testing and interactions. Newbury Park, CA: Sage.

Alloway, T. P., Gathercole, S. E., Kirkwood, H., \& Elliott, J. (2008). Evaluating the validity of the Automated Working Memory Assessment. Educational Psychology, 28, 725-734. doi:10.1080/01443410802243828.

Anderson, P. J. (2008). Towards a developmental model of executive function. In V. Anderson, R. Jacobs, \& P. J. Anderson (Eds.), Executive functions and the frontal lobes: A lifespan perspective (pp. 3-23). New York: Psychology Press.

Archer, J. (2004). Gender differences in aggression in real-world settings: A meta-analytic review. Review of General Psychology, 8, 291-322. doi:10.1037/1089-2680.8.4.291.

Astington, J. W. (2003). Sometimes necessary, never sufficient: False-belief understanding and social competence. In B. Repacholi \& V. Slaughter (Eds.), Individual differences in theory of mind: Implications for typical and atypical development (pp. 13-29). New York: Psychology Press.

Baron-Cohen, S., Leslie, A. M., \& Frith, U. (1985). Does the autistic child have a "theory of mind?" Cognition, 21, 37-46. doi:10.1016/0010-0277(85)90022-8.

Beauchamp, M. H., \& Anderson, V. (2010). SOCIAL: An integrative framework for the development of social skills. Psychological Bulletin, 136, 39-64. doi:10.1037/a0017768.

Björkqvist, K., Österman, K., \& Kaukiainen, A. (1992). The development of direct and indirect aggressive strategies in males and females. In K. Björkqvist \& P. Niemelä (Eds.), Of mice and women: Aspects of female aggression (pp. 51-64). San Diego, CA: Academic Press.

Caputi, M., Lecce, S., Pagnin, A., \& Banerjee, R. (2012). Longitudinal effects of theory of mind on later peer relations: The role of prosocial behavior. Developmental Psychology, 48, 257-270. doi:10.1037/a0025402.

Card, N. A., Stucky, B. D., Sawalani, G. M., \& Little, T. D. (2008). Direct and indirect aggression during childhood and adolescence: A meta-analytic review of gender differences, intercorrelations, and relations to maladjustment. Child Development, 79, 1185-1229. doi:10.1111/j.1467-8624.2008.01184.x.

Carlson, S. M. (2005). Developmentally sensitive measures of executive function in preschool children. Developmental Neuropsychology, 28, 595-616. doi:10.1207/s15326942dn2802_3. 
Crick, N. R., Casas, J. F., \& Ku, H. C. (1999). Relational and physical forms of peer victimization in preschool. Developmental Psychology, 35, 376-385. doi:10.1037/0012-1649.35.2.376.

Crick, N. R., Casas, J. F., \& Mosher, M. (1997). Relational and overt aggression in preschool. Developmental Psychology, 33, 579-588. doi:10.1037/0012-1649.33.4.579.

Dane, A. V., \& Marini, Z. A. (2014). Overt and relational forms of reactive aggression in adolescents: Relations with temperamental reactivity and self-regulation. Personality and Individual Differences, 60, 60-66. doi:10.1016/j.paid.2013.12. 021.

Di Norcia, A., Pecora, G., Bombi, A. S., Baumgartner, E., \& Laghi, F. (2015). Hot and cool inhibitory control in Italian toddlers: Associations with social competence and behavioral problems. Journal of Child and Family Studies, 24, 909-914. doi:10.1007/s10826-014-9901-z.

Dunn, L. M., Whetton, C., \& Pintilie, D. (1982). British picture vocabulary scale. Windsor, UK: NFER-Nelson.

Frey, K. S., Newman, J. B., \& Onyewuenyi, A. C. (2013). Aggressive forms and functions on school playgrounds: Profile variations in interaction styles, bystander actions, and victimization. The Journal of Early Adolescence, 34, 285-310. doi:10.1177/0272431613496638.

Garner, P. W., \& Waajid, B. (2012). Emotion knowledge and self-regulation as predictors of preschoolers' cognitive ability, classroom behavior, and social competence. Journal of Psychoeducational Assessment, 30, 330-343. doi:10.1177/ 0734282912449441.

Gini, G. (2006). Social cognition and moral cognition in bullying: What's wrong? Aggressive Behavior, 32, 528-539. doi: 10.1002/ab.20153.

Gogtay, N., Giedd, J. N., Lusk, L., Hayashi, K. M., Greenstein, D., Vaituzis, A. C., ... Thompson, P. M. (2004). Dynamic mapping of human cortical development during childhood through early adulthood. Proceedings of the National Academy of Sciences, 101, 8174-8179. doi:10.1073/pnas.0402680101.

Goldstein, S., Naglieri, J. A., Princoptta, D., \& Otero, T. M. (2014). Introduction: A history of executive functioning as a theoretical and clinical construct. In S. Goldstein \& J. A. Naglieri (Eds.), Handbook of executive functioning (pp. 3-13). New York: Springer.

Gomes, L., \& Livesey, D. (2008). Exploring the link between impulsivity and peer relations in 5- and 6-year-old children. Child: Care, Health and Development, 34, 763-770. doi:10.1111/j.1365-2214.2008.00878.x.

Gur, R. C., Richard, J., Calkins, M. E., Chiavacci, R., Hansen, J. A., Bilker, W. B., ... Gur, R. E. (2012). Age group and gender differences in performance on a computerized neurocognitive battery in children age 8-21. Neuropsychology, 26, 251265. doi:10.1037/a0026712.

Heilbron, N., \& Prinstein, M. J. (2008). A review and reconceptualization of social aggression: Adaptive and maladaptive correlates. Clinical Child and Family Psychology Review, 11, 176-217. doi:10.1007/s10567-008-0037-9.

Hughes, C., Dunn, J., \& White, A. (1998). Trick or treat?: Uneven understanding of mind and emotion and executive dysfunction in "hard-to-manage" preschoolers. Journal of Child Psychology and Psychiatry, 39, 981-994. doi:10.1111/ 1469-7610.00401.

Hughes, C., Ensor, R., Wilson, A., \& Graham, A. (2010). Tracking executive function across the transition to school: A latent variable approach. Developmental Neuropsychology, 35, 20-36. doi:10.1080/87565640903325691.

Jacobson, L. A., Williford, A. P., \& Pianta, R. C. (2011). The role of executive function in children's competent adjustment to middle school. Child Neuropsychology, 17, 255-280. doi:10.1080/09297049.2010.535654.

Kempes, M., Matthys, W., de Vries, H., \& van Engeland, H. (2005). Reactive and proactive aggression in children: A review of theory, findings and the relevance for child and adolescent psychiatry. European Child \& Adolescent Psychiatry, 14, 11-19. doi:10.1007/s00787-005-0432-4.

Kerr, A., \& Zelazo, P. D. (2004). Development of "hot" executive function: The children's gambling task. Brain and Cognition, 55, 148-157. doi:10.1016/S0278-2626(03)00275-6.

Kim, S., Nordling, J. K., Yoon, J. E., Boldt, L. J., \& Kochanska, G. (2014). Effortful control in "hot" and "cool" tasks differentially predicts children's behaviour problems and academic performance. Journal of Abnormal Child Psychology, 41, 4356. doi:10.1007/s10802-012-9661-4.

Kochanska, G., Murray, K., Jacques, T. Y., Koenig, A. L., \& Vandegeest, K. A. (1996). Inhibitory control in young children and its role in emerging internalization. Child Development, 67, 490-507. doi:10.2307/1131828.

Lagerspetz, K. M. J., Björkqvist, K., \& Peltonen, T. (1988). Is indirect aggression typical of females? Gender differences in aggressiveness in 11- to 12- year-old children. Aggressive Behavior, 14, 403-414. doi:10.1002/1098-2337.

Masten, A. S., Herbers, J. E., Desjardins, C. D., Cutuli, J. J., McCormick, C. M., Sapienza, J. K., ... Zelazo, P. D. (2012). Executive function skills and school success in young children experiencing homelessness. Educational Researcher, 41, 375-384. doi:10.3102/0013189X12459883. 
McQuade, J. D., Murray-Close, D., Shoulberg, E. K., \& Hoza, B. (2013). Working memory and social functioning in children. Journal of Experimental Child Psychology, 115, 422-435. doi:10.1016/j.jecp.2013.03.002.

Monks, C. P., Smith, P. K., \& Swettenham, J. (2005). Psychological correlates of peer victimisation in preschool: Social cognitive skills, executive function and attachment profiles. Aggressive Behavior, 31, 571-588. doi:10.1002/ab.20099.

Moore, C., Barresi, J., \& Thompson, C. (1998). The cognitive basis of future-oriented prosocial behavior. Social Development, 7, 198-219. doi:10.1111/1467-9507.00062.

Ostrov, J. M., \& Crick, N. R. (2007). Forms and functions of aggression during early childhood: A short-term longitudinal study. School Psychology Review, 36, 43-22. doi:10.1007/s10802-007-9179-3.

Ostrov, J. M., \& Godleski, S. A. (2010). Toward an integrated gender-linked model of aggression subtypes in early and middle childhood. Psychological Review, 117, 233-242. doi:10.1037/a0018070.

Ostrov, J. M., Murray-Close, D., Godleski, S. A., \& Hart, E. J. (2013). Prospective associations between forms and functions of aggression and social and affective processes during early childhood. Journal of Experimental Child Psychology, 116, 19-36. doi:10.1016/j.jecp.2012.12.009.

Perner, J., Leekam, S. R., \& Wimmer, H. (1987). 2-year-olds difficulty with false belief-The case for a conceptual deficit. British Journal of Developmental Psychology, 5, 125-137. doi:10.1111/j.2044-835X.1987.tb01048.x.

Poland, S. E., Monks, C. P., \& Tsermentseli, S. (2016). Cool and hot executive function as predictors of aggression in early childhood: Differentiating between the function and form of aggression. British Journal of Developmental Psychology, 34, 181-197. doi:10.1111/bjdp.12122.

Renouf, A., Brendgen, M., Séguin, J. R., Vitaro, F., Boivin, M., Dionne, G., .. Pérusse, D. (2010). Interactive links between theory of mind, peer victimization, and reactive and proactive aggression. Journal of Abnormal Child Psychology, 38, 1109-1123. doi:10.1007/s10802-010-9432-z.

Russell, A., Hart, C., Robinson, C., \& Olsen, S. (2003). Children's sociable and aggressive behaviour with peers: A comparison of the US and Australia, and contributions of temperament and parenting styles. International Journal of Behavioral Development, 27, 74-86. doi:10.1080/01650250244000038.

Shallice, T. (1982). Specific impairments of planning. Philosophical Transactions of the Royal Society of London, B, 298, 199209. doi:10.1098/rstb.1982.0082.

Simpson, A., \& Riggs, K. J. (2006). Conditions under which children experience inhibitory difficulty with a "'button-press"” go / no-go task. Journal of Experimental Child Psychology, 94, 18-26. doi:10.1016/j.jecp.2005.10.003.

Smith, R. L., Rose, A. J., \& Schwartz-Mette, R. A. (2009). Relational and overt aggression in childhood and adolescence: Clarifying mean-level gender differences and associations with peer acceptance. Social Development, 19, 243-269. doi: 10.1111/j.1467-9507.2009.00541.x.

Spieker, S. J., Campbell, S. B., Vandergrift, N., Pierce, K. M., Cauffman, E., Susman, E. J., \& Roisman, G. I. (2012). Relational aggression in middle childhood: Predictors and adolescent outcomes. Social Development, 21, 354-375. doi:10.1111/ j.1467-9507.2011.00631.x.

Terranova, A. M., Morris, A. S., \& Boxer, P. (2008). Fear reactivity and effortful control in overt and relational bullying: A six-month longitudinal study. Aggressive Behavior, 34, 104-115. doi:10.1002/ab.20232.

Tremblay, R. E. (2000). The development of agressive behaviour during childhood: What have we learned in the past century? International Journal of Behavioral Development, 24, 129-141. doi:10.1080/016502500383232.

Utendale, W. T., Hubert, M., Saint-Pierre, A. B., \& Hastings, P. D. (2011). Neurocognitive development and externalizing problems: The role of inhibitory control deficits from 4 to 6 years. Aggressive Behavior, 37, 476-488. doi:10.1002/ab.20403.

Vaillancourt, T., Miller, J. L., Fagbemi, J., Côtè, S., \& Tremblay, R. E. (2007). Trajectories and predictors of indirect aggression: Results from a nationally representative longitudinal study of Canadian children aged 2-10. Aggressive Behavior, 33, 314-326. doi:10.1002/ab.20202.

Véronneau, M. H., Vitaro, F., Brendgen, M., Dishion, T. J., \& Tremblay, R. E. (2010). Transactional analysis of the reciprocal links between peer experiences and academic achievement from middle childhood to early adolescence. Developmental Psychology, 46, 773-790. doi:10.1037/a0019816.

Walker, S. (2005). Gender differences in the relationship between young children's peer-related social competence and individual differences in theory of mind. The Journal of Genetic Psychology, 166, 297-312. doi:10.3200/GNTP.166.3.297-312.

Warnes, E. D., Sheridan, S. M., Geske, J., \& Warnes, W. A. (2005). A contextual approach to the assessment of social skills: Identifying meaningful behaviors for social competence. Psychology in the Schools, 42, 173-187. doi:10.1002/ pits.20052.

Wechsler, D. (1991). Wechsler intelligence scale for children-Third Edition. San Antonio, TX: Psychological Corporation.

Wellman, H. M., Cross, D., \& Watson, J. (2001). Meta-analysis of theory-of-mind development: The truth about false belief. Child Development, 72, 655-684. doi:10.1111/1467-8624.00304. 
Werner, R. S., Cassidy, K. W., \& Juliano, M. (2006). The role of social-cognitive abilities in preschoolers' aggressive behaviour. British Journal of Developmental Psychology, 24, 775-799. doi:10.1348/026151005X78799.

Willoughby, M., Kupersmidt, J., Voegler-Lee, M., \& Bryant, D. (2011). Contributions of hot and cool self-regulation to preschool disruptive behavior and academic achievement. Developmental Neuropsychology, 36, 162-180. doi:10.1080/ 87565641.2010.549980.

Wimmer, H., \& Perner, J. (1983). Beliefs about beliefs: Representation and constraining function of wrong beliefs in young children's understanding of deception. Cognition, 13, 103-128. doi:10.1016/0010-0277(83)90004-5.

Yagmurlu, B. (2013). Relations among sociocognitive abilities and prosocial behavior. Journal of Child and Family Studies, 23, 591-603. doi:10.1007/s10826-013-9726-1.

Yeates, K. O., Bigler, E. D., Dennis, M., Gerhardt, C. A., Rubin, K. H., Stancin, T., .. Vannatta, K. (2007). Social outcomes in childhood brain disorder: A heuristic integration of social neuroscience and developmental psychology. Psychological Bulletin, 133, 535-556. doi:10.1037/0033-2909.133.3.535.

Zelazo, P. D., \& Müller, U. (2002). Executive function in typical and atypical development. In U. Goswami (Ed.), Handbook of childhood cognitive development (pp. 445-470). Oxford: Blackwell Publising Ltd.

Zelazo, P. D., Qu, L., \& Müller, U. (2005). Hot and cool aspects of executive function: Relations in early development. In W. Schneider, R. Schumann-Hengsteler, \& B. Sodian (Eds.), Young children's cognitive development: Interrelationships among executive functioning, working memory, verbal ability and theory of mind (pp. 71-95). Mahwah, NJ: Lawrence Erlbaum Associates Inc.

Zimmer-Gembeck, M. J. (2005). Relational and physical aggression, prosocial behavior, and peer relations: Gender moderation and bidirectional associations. The Journal of Early Adolescence, 25, 421-452. doi:10.1177/0272431605279841. 